Please do not remove this page

RMIT

UNIVERSITY

\title{
Factors associated with conflicting findings on acupuncture for tension-type headache: Qualitative and quantitative analyses
}

Hao, Xinyu; Xue, Charlie Changli; Dong, Lin; Zheng, Zhen

https://researchrepository.rmit.edu.au/esploro/outputs/9921858925101341/filesAndLinks?institution=61RMIT_INST\&index=null

Hao, X., Xue, C. C., Dong, L., \& Zheng, Z. (2012). Factors associated with conflicting findings on acupuncture for tension-type headache: Qualitative and quantitative analyses. Journal of Alternative and Complementary Medicine, 19(4), 285-297. https://doi.org/10.1089/acm.2011.0914

Document Version: Published Version

Published Version: https://doi.org/10.1089/acm.2011.0914

Repository homepage: https://researchrepository.rmit.edu.au

(C) 2012 Mary Ann Liebert

Downloaded On 2023/04/26 21:52:54 +1000

Please do not remove this page 
Thank you for downloading this document from the RMIT Research Repository.

The RMIT Research Repository is an open access database showcasing the research outputs of RMIT University researchers.

RMIT Research Repository: http://researchbank.rmit.edu.au/

\section{Citation:}

Hao, X, Xue, C, Dong, L and Zheng, Z 2012, 'Factors associated with conflicting findings on acupuncture for tension-type headache: Qualitative and quantitative analyses', Journal of Alternative and Complementary Medicine, vol. 19, no. 4, pp. 285-297.

See this record in the RMIT Research Repository at:

http://researchbank.rmit.edu.au/view/rmit:18685

Version: Published Version

Copyright Statement: (c) 2012 Mary Ann Liebert

Link to Published Version:

http://dx.doi.org/10.1089/acm.2011.0914 


\title{
Factors Associated with Conflicting Findings on Acupuncture for Tension-Type Headache: Qualitative and Quantitative Analyses
}

\author{
Xinyu (Alan) Hao, BMed, PhD (cand), Charlie Changli Xue, BMed, PhD, \\ Lin Dong, BMed, MAppSc, and Zhen Zheng, BMed, PhD
}

\begin{abstract}
Objectives: This study aimed to identify the factors that might have contributed to the conflicting outcomes about the efficacy of acupuncture for tension-type headache (TTH) through systematically reviewing relevant randomized controlled trials.

Methods: Thirteen (13) databases were searched from their inception until August 2010. There were no restrictions on language or year of publication. Included studies were randomized controlled trials comparing real with sham acupuncture, with patient selection guided by the International Headache Classification, and reported headache days. Meta-analyses and subgroup analyses were undertaken to compare the effects of real and sham acupuncture interventions and the effects of acupuncture with various needling techniques and treatment modes.

Results: Forty-three (43) studies were retrieved for further assessment from 120 potential studies. Finally, five studies of high methodological quality were included in this review. Standard mean difference (SMD) of the included studies showed no statistical significance between real and sham acupuncture $(-0.31 ; 95 \%$ confidence interval $[\mathrm{CI}]-0.72$ to 0.09$)$, however, the heterogeneity among the studies was high $\left(\mathrm{I}^{2}=81 \%\right)$. Subgroup analyses reduced heterogeneity, and showed that electro-acupuncture (SMD-1.60; $95 \% \mathrm{CI}-2.33$ to -0.88 ) to be more efficacious than manual acupuncture (SMD $-0.13 ; 95 \%$ CI -0.41 to 0.14 ); needle retention with 30 minutes (SMD-0.46; 95\% CI - 0.87 to -0.06) being better than no needle retention (SMD 0.45; 95\% CI -0.11, 1.01); and twice-a-week treatment (SMD - 0.46; 95\% CI - 0.87 to -0.06) was better than once-a-week treatment (SMD 0.45; $95 \%$ CI $-0.11,1.01)$.

Conclusions: Acupuncture stimulation mode, needle retention, and treatment frequency could be important factors contributing to the outcome of acupuncture for TTH. Further studies are warranted to determine treatment parameters to ensure effective translation of RCTs outcomes of acupuncture for patients with TTH.
\end{abstract}

\section{Introduction}

A CUPUNCTURE HAS BEEN WIDELY USED to relieve headache, but trials on acupuncture for tension-type headache (TTH) have produced conflicting results. A recent Cochrane Library Systematic Review concludes that acupuncture is valuable for the management of $\mathrm{TTH}^{1}{ }^{1}$ Results of shamacupuncture controlled trials, however, showed inconsistent results. Some trials conclude that real acupuncture is significantly better than sham intervention, ${ }^{2,3}$ whereas others have not found a statistically significant difference between the two. ${ }^{4-7}$ A consensus on whether real acupuncture is superior to sham acupuncture has not been reached..$^{8-12}$
Acupuncture is a complex intervention. Its active ingredients are not well defined. ${ }^{13,14}$ A recent Delphi study of expert opinions on the essential components of quality acupuncture treatment has identified 14 domains with 26 items, including needle stimulation mode, treatment duration, frequency of treatment, practitioner training, and trial monitoring. ${ }^{15}$

To improve the quality of efficacy research on acupuncture for TTH, there is a need to identify factors contributing to the inconsistent outcomes (for instance, the adequacy and administration of trial acupuncture treatments). This systematic review aimed to identify the factors contributing to conflicting findings through conducting a meta-analysis and 
subgroup analyses comparing the effects of real and sham acupuncture on TTH. Specifically, this review explored the effect of the factors that have been considered to have direct impact on the quality of acupuncture trial as described elsewhere. ${ }^{15}$ These factors are mode of acupuncture, manipulation of needle, frequency of treatment, and the number of trial centers, and other factors identified through qualitative assessment of the included studies.

\section{Methods}

\section{Search strategy}

Thirteen (13) major databases were searched consisting of four leading Chinese databases (CNKI, CQVIP, Wanfang database, and CBM) and nine English databases (Pubmed, Embase, CINAHL, Proquest, Cochrane library, Acubriefs, Science direct, SCOPUS, Informit) up to August 2010. There were no restrictions on year or language of publication. The search terms were the following: tension-type headache, acupuncture, randomized controlled trial, and their variations. A sample strategy is included in Table 1.

\section{Selection criteria}

Included studies (1) were randomized or quasirandomized controlled trials (RCTs or quasi-RCTs); (2) had adult patients with TTH diagnosed according to International Headache Society (IHS) criteria or Ad Hoc committee's criteria; (3) reported headache days as an outcome mea-

\section{Table 1. Sample Strategy of Searching Databases}

\begin{tabular}{|c|c|}
\hline $\begin{array}{l}\text { A. Search strategy } \\
\text { to locate "tension- } \\
\text { type headache" }\end{array}$ & $\begin{array}{l}\text { \# 1. tension-type headache }[\mathrm{MeSH}] \\
\# \text { 2. tension headache }[\mathrm{tw}] \\
\# \text { 3. headache }[\mathrm{MeSH}] \\
\# \text { 4. TTH }[\mathrm{tw}] \\
\# \text { 5. TH [tw] } \\
\# \text { 6. or } \# \text { 1-\# } 5\end{array}$ \\
\hline $\begin{array}{l}\text { B. Search strategy } \\
\text { to locate } \\
\text { acupuncture } \\
\text { interventions }\end{array}$ & $\begin{array}{l}\text { \# 7. acupuncture }[\mathrm{MeSH}] \\
\# \text { 8. acupuncture therapy }[\mathrm{MeSH}] \\
\# \text { 9. electroacupuncture }[\mathrm{MeSH}] \\
\# \text { 10. electro-acupuncture }[\mathrm{tw}] \\
\# \text { 11. brief needling }[\mathrm{tw}] \\
\# \text { 12. dry needling [tw] } \\
\text { \# 13. electrical acupuncture }[\mathrm{tw}] \\
\# \text { 14. acupuncture points }[\mathrm{MeSH}] \\
\# \text { 15. body acupuncture }[\mathrm{tw}] \\
\# \text { 16. scalp acupuncture }[\mathrm{tw}] \\
\# \text { 17. routine acupuncture }[\mathrm{tw}] \\
\# \text { 18. manual acupuncture }[\mathrm{tw}] \\
\# \text { 19. abdomen acupuncture }[\mathrm{tw}] \\
\# \text { 20. or/\#7-\#19 }\end{array}$ \\
\hline $\begin{array}{l}\text { C. Search strategy } \\
\text { to locate RCTs } \\
\text { or semi-RCT }\end{array}$ & $\begin{array}{l}\text { \# 21. Randomized } \\
\text { Controlled Trial [MeSH] } \\
\text { \# 22. RCT [tw] } \\
\text { \# 23. Controlled Trial [tw] } \\
\text { \# 24. CT [tw] } \\
\text { \# 25. or/\#21-\#24 }\end{array}$ \\
\hline $\begin{array}{l}\text { D. Search strategy } \\
\text { to locate studies } \\
\text { for this review }\end{array}$ & \#6 AND \#20 AND \#25 \\
\hline
\end{tabular}

RCTs, randomized controlled trials. surement; (4) employed invasive acupuncture needling; and (5) needled acupoints, Ashi point, and/or trigger/tender points. Studies were excluded if (1) they did not have a sham acupuncture control group; (2) point injections were used because it is difficult to differentiate if the efficacy was from medication or acupuncture itself; (3) dry-needling was employed because its theory and practice is not in accordance with traditional acupuncture; or (4) results about participants with TTH were reported separately from those with other types of headache, such as migraine.

\section{Outcome measure}

The outcome measure was headache days ${ }^{16}$ at the end of the treatment and follow-ups.

\section{Data extraction}

Two (2) reviewer authors (XYH, LD) extracted data from eligible trials independently. Major characteristics including methods, participants, interventions, and outcome measures were recorded for analysis. Other information including protocols of treatment and selection criteria was also extracted for study comparisons. Disagreements were solved by discussion and consult with a third reviewer (ZZ).

\section{Assessment of methodological quality}

The methodological quality of each study was assessed by 2 reviewers (XYH and LD) using Jadad Scale, ${ }^{17}$ Internal Validity Scale (IVS), ${ }^{18}$ and the Oxford Pain Validity Scale (OPVS). ${ }^{19}$ Additionally, allocation concealment was ranked as A: adequate, B: unclear, C: inadequate, and D: not used. ${ }^{20}$ A study with a score of 3 or more points on a Jadad scale is considered high quality. Similarly, with IVS and OPVS rating, studies reaching $60 \%$ of the total scores can be regarded as high quality. ${ }^{21}$

\section{Data analysis and synthesis}

Review Manager 5.1 was used for meta-analysis. Assessment of heterogeneity was evaluated using the $\mathrm{I}^{2}$ test; a low, moderate, and high $\mathrm{I}^{2}$ value was indicated by $25 \%$, $50 \%$, and $75 \%$, respectively. ${ }^{22}$ A random-effect model was used if significant heterogeneity $\left(\mathrm{I}^{2} \geq 50 \%\right)$ among the trials was detected. For continuous data, weight or standard mean difference (SMD) was used. When different scales were used for assessing one outcome measure, SMD was calculated.

\section{Subgroup analysis}

When heterogeneity was high, qualitative data were examined to identify the potential sources. Subgroup analyses were then conducted to verify the sources. ${ }^{20}$

\section{Results}

\section{Search result and eligibility}

Five (5) of 120 trials involving 838 TTH participants ${ }^{3-5,23,24}$ were selected, and the remaining were excluded because they reported invalid outcome measures, were duplications, had invalid interventions, or did not use IHS diagnostic criteria (see Supplementary Table online at www.liebertpub.com/ acm). Figure 1 outlines the study selection. 


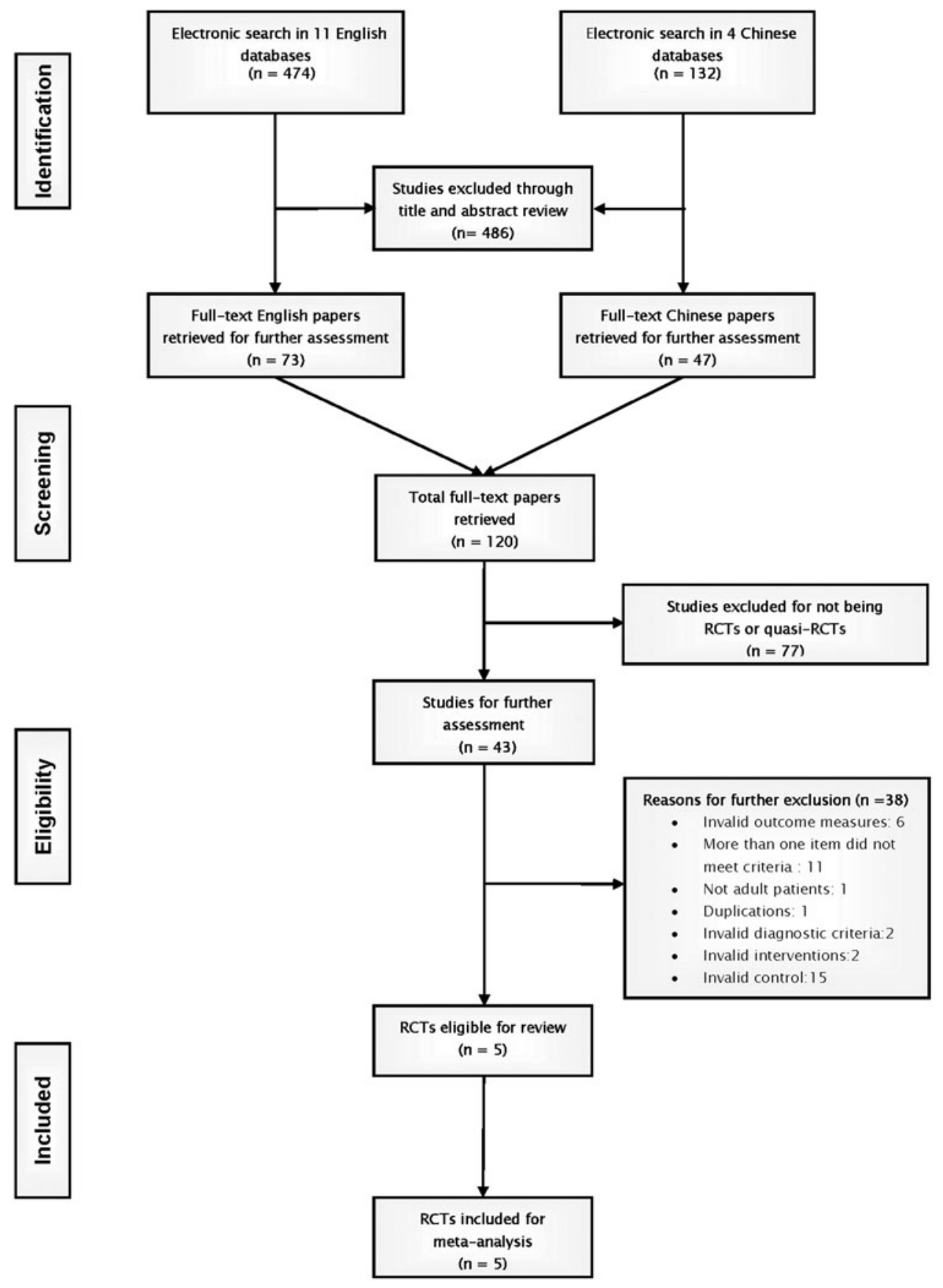

FIG. 1. Flowchart of study selection. RCTs, randomized controlled trials.

\section{Study characteristics}

The characteristics of the five trials are listed in Table 2. Three $(3)^{5,24,25}$ were conducted in Germany, and the remaining two ${ }^{3,23}$ were from the United Kingdom and Australia, respectively. The sample size ranged from 40 to 409 , with three multicenter trials ${ }^{5,24,25}$ having a larger sample size. There were more females than males in the studies. The average age of the participants ranged from 30 to 50 years. $3,5,23,25$

\section{Quality of the trials}

Scores of Jadad, IVS, and OPVS are presented in Table 2. Based on the Jadad sores, all five studies were of high methodological quality. There was a high correlation between Jadad and IVS scores $(r=0.97 p=0.006)$, but not between either Jadad and OPVS or IVS and OPVS. There was no correlation between methodology quality and treatment effect.

\section{Characteristics of acupuncture treatments}

Details of acupuncture treatments are presented in Table 3. One (1) study ${ }^{3}$ used electroacupuncture (EA) and selected distal points only, whereas the rest $t^{5,23-25}$ chose manual acupuncture (MA) using both local and distal points.

Four (4) studies $3,5,24,25$ had 30 minute-needle retention with de qi sensation, whereas one applied 15 seconds of 


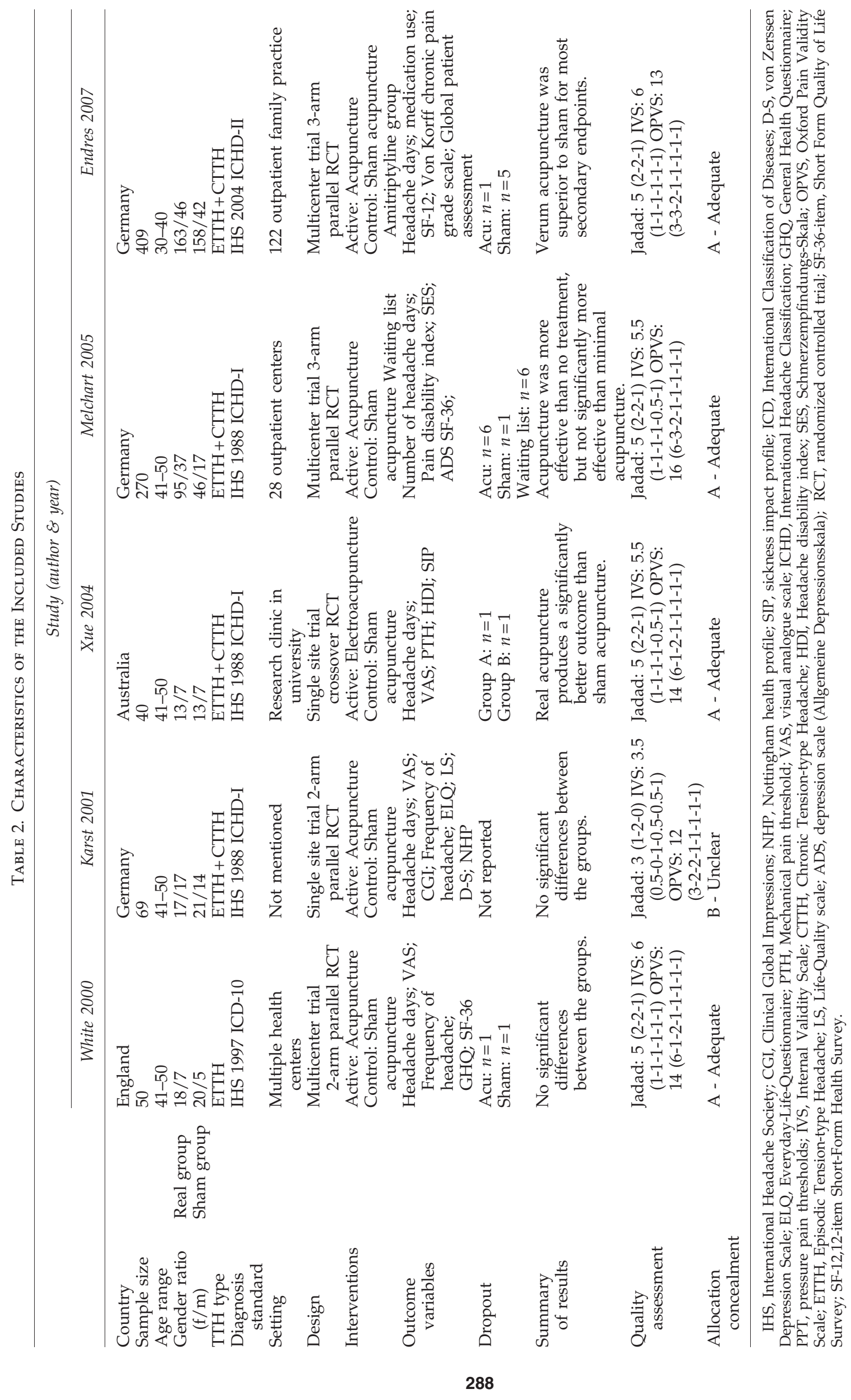




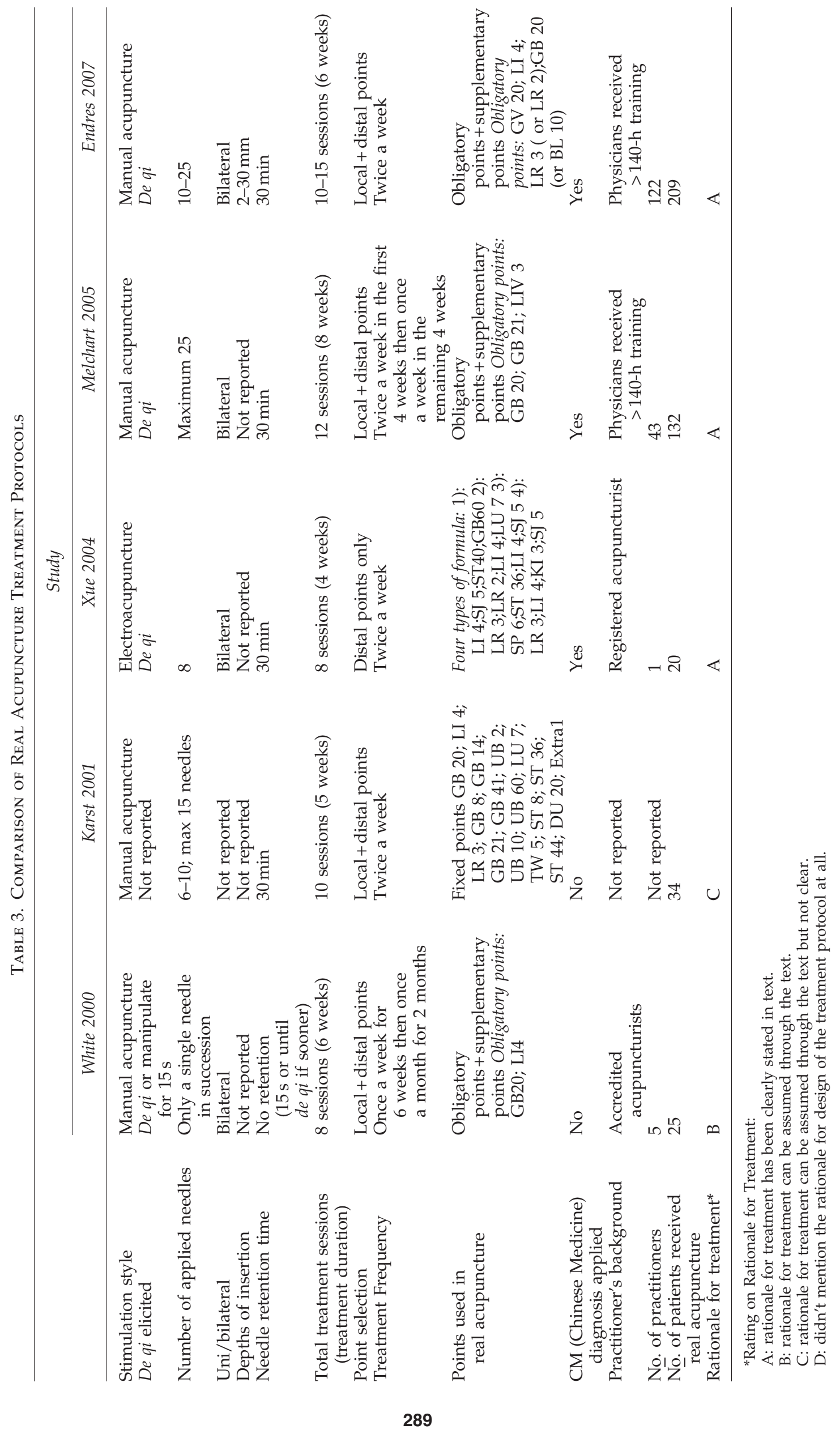


needling stimulation without intention to obtain de qi or needle retention. ${ }^{25}$

Treatment sessions range from 8 to 15 over $4-8$ weeks, with weekly or twice-a-week treatment. Three (3) studies applied pulse and tongue diagnosis or Chinese medicine (CM) diagnostic questionnaires. ${ }^{3,5,24}$ All trials reported number and training background of practitioners except for one. ${ }^{25}$ Four (4) studies intended to achieve individualized treatment through semistructured protocols,,$^{3,5,23,24}$ and one used fixed points for all patients. ${ }^{25}$

A comparison of sham acupuncture is provided in Table 4. All studies used nonacupuncture points and applied the same needle retention time as that in the real acupuncture treatment. Three $(3)^{3,5,24}$ avoided using any points on the head. Three $(3)^{3,4,24}$ used an invasive method, by means of superficial insertion onto on nonpoints without de qi. The other two studies ${ }^{23,25}$ used a noninvasive method.

\section{Efficacy of acupuncture in headache days}

All five studies ${ }^{3,5,23-25}$ were included in the meta-analysis. SMD was calculated because one study reported headache days per week ${ }^{23}$; two studies ${ }^{3,25}$ reported headache days per month; and the other two studies ${ }^{5,24}$ reported headache days per 4 weeks.

Results are presented in Figure 2. Real and sham acupuncture groups were not statistically different at any time point with regard to headache days. A high heterogeneity $(p=0.0004$; $\mathrm{I}^{2}=81 \%$ ) was identified at the end of the treatment. Low heterogeneities were presented for analyses of short-term and longterm follow-up periods $\left(\mathrm{I}^{2}=33 \%\right.$ and $\mathrm{I}^{2}=30 \%$, respectively).

\section{Subgroup analyses and investigation of heterogeneity}

Subgroup analyses were conducted to examine the source of heterogeneity according to qualitative data of the features of acupuncture treatments (Table 5).

Table 4. Comparison of Sham Acupuncture Procedures

\begin{tabular}{|c|c|c|c|c|c|}
\hline \multirow{3}{*}{$\begin{array}{l} \\
\\
\text { Invasive } \\
\quad \text { needling } \\
\text { method } \\
\text { used? }\end{array}$} & \multicolumn{5}{|c|}{ Study } \\
\hline & White 2000 & Karst 2001 & Xие 2004 & Melchart 2005 & Endres 2007 \\
\hline & No & No & Yes & Yes & Yes \\
\hline $\begin{array}{l}\text { Stimulation } \\
\text { style }\end{array}$ & $\begin{array}{l}\text { Blunted cocktail- } \\
\text { stick tapped } \\
\text { in by avoiding } \\
\text { tender area } \\
\text { and acupoints }\end{array}$ & $\begin{array}{l}\text { Blunt needle inserted } \\
\text { on the real points } \\
\text { in real group through } \\
\text { a cube-shaped elastic } \\
\text { foam to cause a } \\
\text { pricking sensation } \\
\text { without actually } \\
\text { puncturing the skin }\end{array}$ & $\begin{array}{l}\text { Superficial } \\
\text { insertion by } \\
\text { same needle } \\
\text { with real } \\
\text { intervention } \\
\text { with very low } \\
\text { frequency }\end{array}$ & $\begin{array}{l}\text { Superficial } \\
\text { needling by } \\
\text { same type of } \\
\text { needle with } \\
\text { real group }\end{array}$ & $\begin{array}{l}\text { Superficial } \\
\text { insertion by } \\
\text { same type of } \\
\text { needle with } \\
\text { real group }\end{array}$ \\
\hline $\begin{array}{l}\text { Points } \\
\text { on head? }\end{array}$ & $\begin{array}{l}\text { Yes } \\
\text { Sham points are } \\
4 \text { standard areas } \\
\text { (2 selected from } \\
\text { the occipital } \\
\text { protuberances, } \\
\text { spines of scapula, } \\
\text { vertex of skull and } \\
\text { spinous process } \\
\text { of } 6 \text { th cervical } \\
\text { vertebra, and } \\
2 \text { areas at the } \\
\text { middle of } 2 \text { nd } \\
\text { metacarpal bone } \\
\text { of each hand) }\end{array}$ & $\begin{array}{l}\text { Yes } \\
\text { Same points as } \\
\text { the real acupoints. } \\
\text { include: GB20 LI4 } \\
\text { LR3 GB8 GB14 } \\
\text { GB21 GB41 BL2 } \\
\text { BL10 BL60 LU7 } \\
\text { TE5 ST8 ST36 } \\
\text { ST44 GV20 } \\
\text { Extra1 (Yintang) }\end{array}$ & No & No & No \\
\hline $\begin{array}{l}\text { Location } \\
\text { of points }\end{array}$ & $\begin{array}{l}\text { 5-10 mm away } \\
\text { from real points }\end{array}$ & $\begin{array}{l}\text { Same points } \\
\text { used in } \\
\text { real group }\end{array}$ & $\begin{array}{l}\text { 5-10 } \mathrm{mm} \text { away } \\
\text { from real points }\end{array}$ & Nonacupoints & Nonacupoints \\
\hline $\begin{array}{l}\text { Manipulation } \\
\text { on needle }\end{array}$ & $\begin{array}{l}\text { Gentle pressure } \\
\text { while rotating } \\
\text { for } 15 \text { seconds } \\
\text { on each }\end{array}$ & Not mentioned & $\begin{array}{l}\text { No further } \\
\text { manipulation }\end{array}$ & $\begin{array}{l}\text { Avoid manual } \\
\text { stimulation }\end{array}$ & $\begin{array}{l}\text { No } \\
\text { stimulation }\end{array}$ \\
\hline $\begin{array}{l}\text { Needle } \\
\text { retention } \\
\text { time }\end{array}$ & $\begin{array}{l}\text { Manipulate for } \\
15 \text { seconds } \\
\text { (without } \\
\text { retention) }\end{array}$ & 30 minutes & 30 minutes & 30 minutes & 30 minutes \\
\hline De qi elicited & Not mentioned & Not mentioned & Avoid de qi & Avoid de qi & Avoid de qi \\
\hline
\end{tabular}




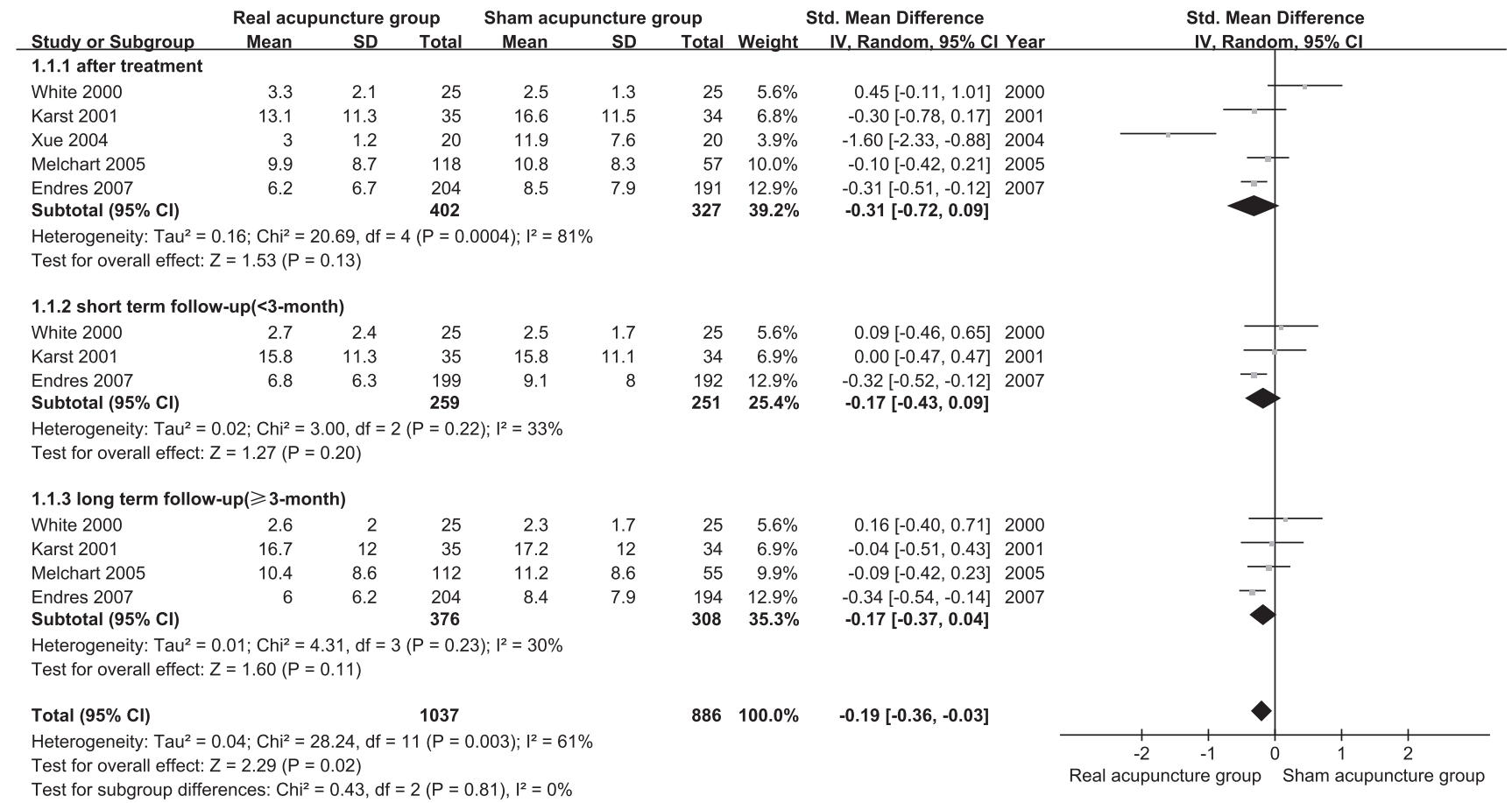

FIG. 2. Forest plot: Acupuncture versus sham acupuncture, outcome: Headache days. SD, standard deviation; CI, confidence interval.

Type of acupuncture (EA versus MA). When four ${ }^{5,23-25}$ MA studies were compared with one EA study, there was a statistically significant subgroup difference favoring EA. The overall heterogeneity was moderate $\left(\mathrm{I}^{2}=57 \%\right)$ (Fig. 3A). After the removal of White's study, which had no needle retention, the heterogeneity was reduced. The subgroup difference remained statistically significant $\left(\chi^{2}=12.69\right.$, $p=0.0004)$ (Fig. 3B).

Needle retention (30 minutes versus no retention). Four (4) studies $3,5,24,25$ with 30-minute needle retention with de qi sensation were compared with one study with 15 seconds of

Table 5. Results of Subgroup Analyses (After Treatment)

\begin{tabular}{ccccc}
\hline Outcome title & $\begin{array}{c}\text { Number } \\
\text { of studies of patients }\end{array}$ & $\begin{array}{c}\text { Effect size } \\
\text { SMD }(95 \% \mathrm{CI})\end{array}$ & $\begin{array}{c}\text { Test for overall } \\
\text { effect p-value }\end{array}$ & Heterogeneity \\
\hline
\end{tabular}

\section{Type of acupuncture (EA vs. MA)}

Before removal EA

After removal MA of White 2000

2. Needle retention (No retention vs. 30 minutes retention)

Before removal Needle retention 50 not applied

Needle retention applied $\quad 4 \quad 679$ for 30 minutes

After removal Needle retention applied 3 of Xue 2004 for 30 minutes

\section{Treatment frequency (twice a week vs. once a week)}

Before removal Once a week

Twice a week

After removal Twice a week

$\begin{array}{lll}\text { Twice a week } & 3 & 639\end{array}$

40

689

639

50

679

639

$$
\begin{array}{ll}
-1.60[-2.33,-0.88] & p<0.0001 \\
-0.13[-0.41,0.14] & p=0.33 \\
-0.26[-0.42,-0.10] & p=0.001
\end{array}
$$

$$
\begin{gathered}
\mathrm{N} / \mathrm{A} \\
\mathrm{I}^{2}=57 \% ; \mathrm{Tau}^{2}=0.04 \\
\mathrm{I}^{2}=0 \% ; \mathrm{Tau}^{2}=0.00
\end{gathered}
$$

$$
\begin{aligned}
0.45[-0.11,1.01] & p=0.12 \\
-0.46[-0.87,-0.06] & p=0.02 \\
-0.26[-0.42,-0.10] & p=0.001
\end{aligned}
$$

$$
\begin{aligned}
& \mathrm{I}^{2}=78 \% ; \mathrm{Tau}^{2}=0.12 \\
& \mathrm{I}^{2}=0 \% ; \mathrm{Tau}^{2}=0.00
\end{aligned}
$$
of Xue 2004

4. Center of study (multicenter vs. single site)

Before removal Single-site trial

Multicenter trial

After removal Multicenter trial of White 2000

50
679
639

$0.45[-0.11,1.01] \quad p=0.12$

$-0.46[-0.87,-0.06] p=0.02$

$-0.26[-0.42,-0.10] p=0.001$

$\mathrm{N} / \mathrm{A}$

$\mathrm{I}^{2}=78 \% ; \mathrm{Tau}^{2}=0.12$

$\mathrm{I}^{2}=0 \% ; \mathrm{Tau}^{2}=0.00$

SMD, standard mean difference; CI, confidence interval; EA, electroacupuncture; MA, manual acupuncture; N/A, not applicable. 
A

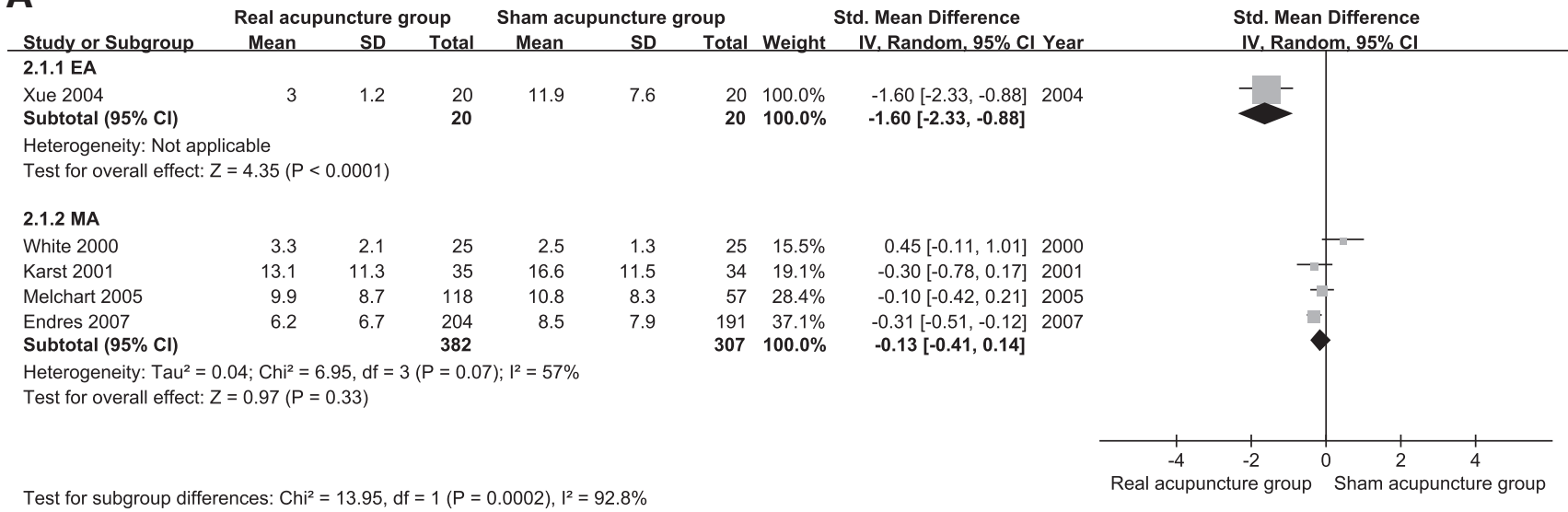

B

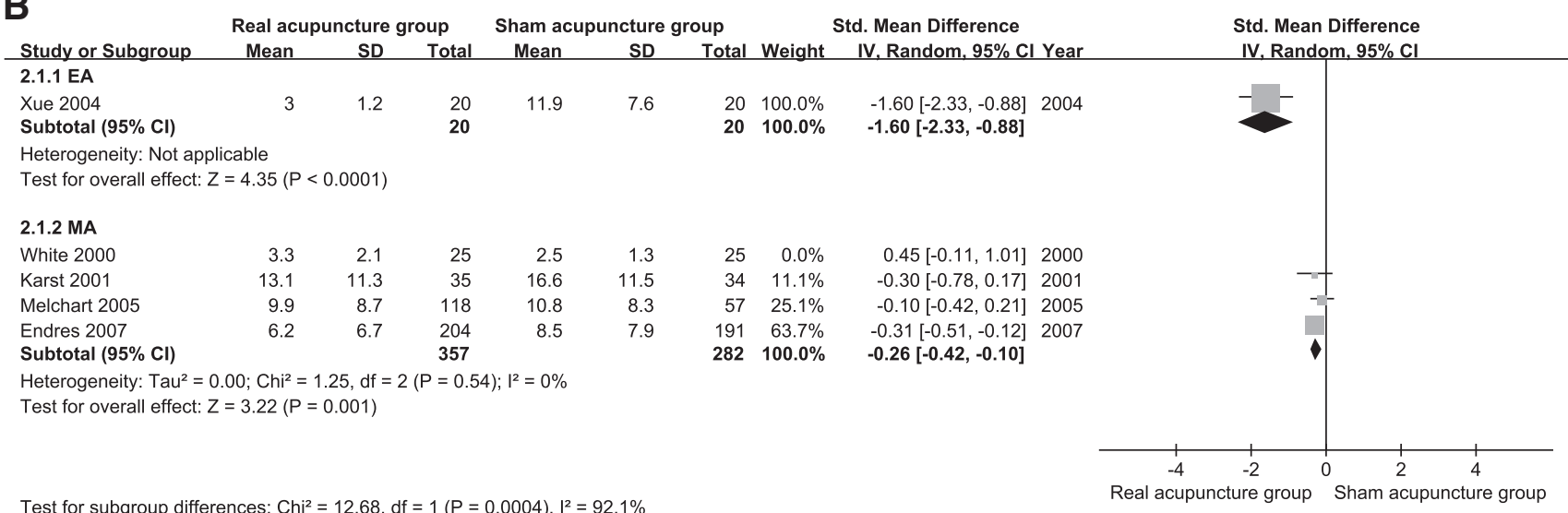

C

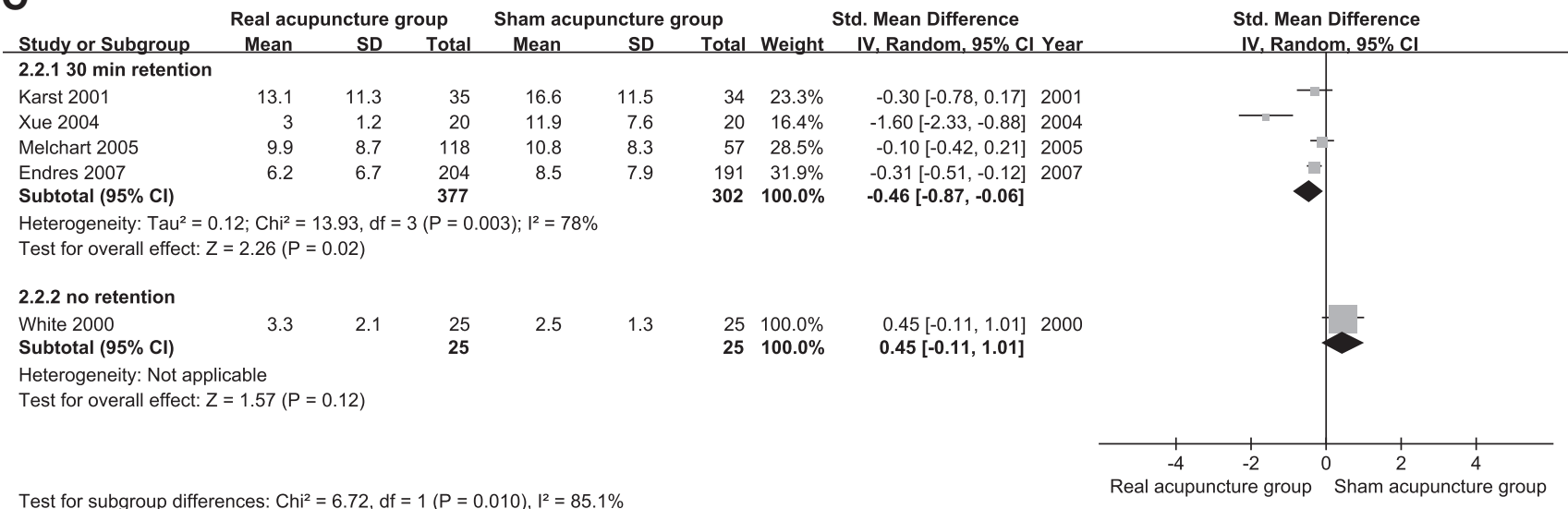

FIG. 3. Exploration of the sources of heterogeneity. A and B: Type of acupuncture (electroacupuncture [EA] versus manual acupuncture $[\mathrm{MA}])$. C and D: Needle retention (30 minutes versus no retention). Frequency of treatment (twice a week versus once a week). E and F: Number for study center (multicenter versus single site). SD, standard deviation; CI, confidence interval.

needling. ${ }^{25}$ There was a high heterogeneity $\left(\mathrm{I}^{2}=78 \%\right)$ (Fig. $3 C)$. After the removal of the EA study, heterogeneity was reduced $\left(\mathrm{I}^{2}=0 \%\right)$. Among the remaining four MA studies, there was a statistically significant subgroup difference between studies having 30-minute retention and those with no needle retention $\left(\chi^{2}=5.70, p=0.02\right)$ favoring longer needle retention (Fig. 3D).
Frequency of treatment (twice a week vs. once a week). Four (4) studies $3,5,24,25$ with twice-a-week treatment sessions were compared with one study having weekly treatment. ${ }^{25}$ This subgroup analysis involved exactly the same studies as in the comparison of needle retention, and the same result was obtained (Figs. 3C and $3 \mathrm{D})$. 


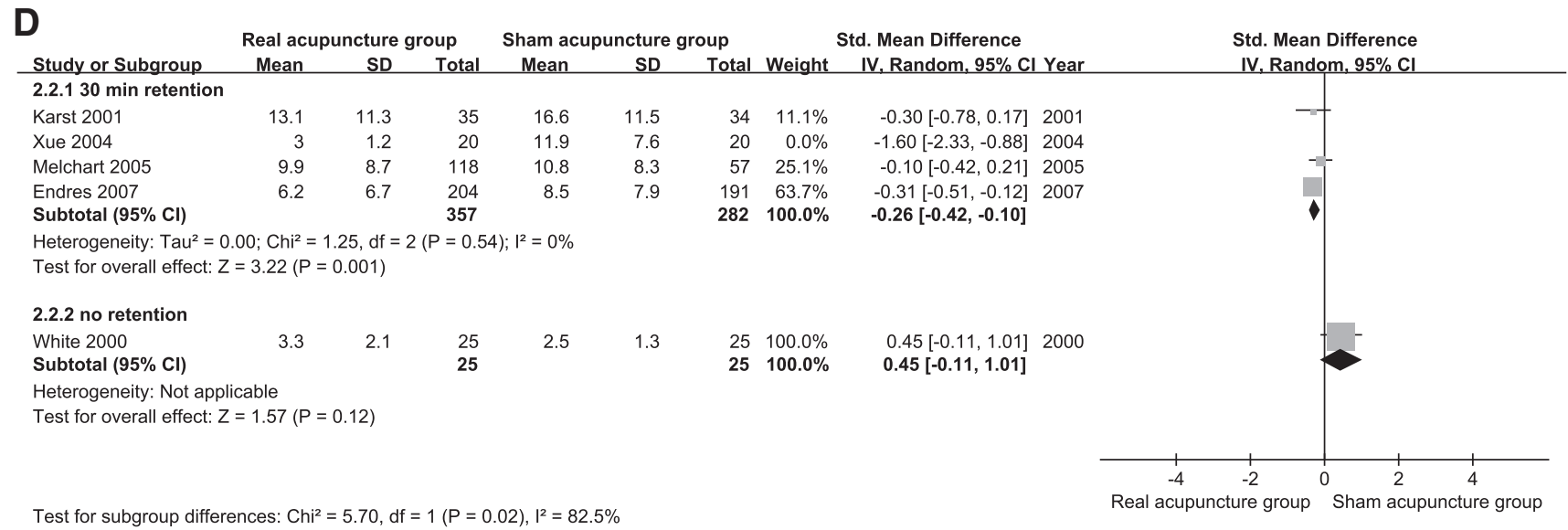

\begin{tabular}{|c|c|c|c|c|c|c|c|c|c|}
\hline \multirow[b]{2}{*}{ Study or Subgroup } & \multicolumn{3}{|c|}{ Real acupuncture group } & \multicolumn{3}{|c|}{ Sham acupuncture group } & \multicolumn{3}{|c|}{ Std. Mean Difference } \\
\hline & Mean & SD & Total & Mean & SD & Total & Weight & IV. Random, $95 \% \mathrm{Cl}$ & I Year \\
\hline \multicolumn{10}{|l|}{ 2.4.1 multicentre } \\
\hline White 2000 & 3.3 & 2.1 & 25 & 2.5 & 1.3 & 25 & $21.9 \%$ & $0.45[-0.11,1.01]$ & 2000 \\
\hline Melchart 2005 & 9.9 & 8.7 & 118 & 10.8 & 8.3 & 57 & $35.4 \%$ & $-0.10[-0.42,0.21]$ & 2005 \\
\hline Endres 2007 & 6.2 & 6.7 & 204 & 8.5 & 7.9 & 191 & $42.7 \%$ & $-0.31[-0.51,-0.12]$ & 2007 \\
\hline Subtotal $(95 \% \mathrm{Cl})$ & & & 347 & & & 273 & $100.0 \%$ & $-0.07[-0.43,0.28]$ & \\
\hline \multicolumn{10}{|c|}{$\begin{array}{l}\text { Heterogeneity: } \mathrm{Tau}^{2}=0.07 ; \mathrm{Chi}^{2}=6.77, \mathrm{df}=2(\mathrm{P}=0.03) ; \mathrm{I}^{2}=70 \% \\
\text { Test for overall effect: } Z=0.40(P=0.69)\end{array}$} \\
\hline \multicolumn{10}{|l|}{ 2.4.2 single centre } \\
\hline Karst 2001 & 13.1 & 11.3 & 35 & 16.6 & 11.5 & 34 & $52.3 \%$ & $-0.30[-0.78,0.17]$ & 2001 \\
\hline Xue 2004 & 3 & 1.2 & 20 & 11.9 & 7.6 & 20 & $47.7 \%$ & $-1.60[-2.33,-0.88]$ & 2004 \\
\hline Subtotal $(95 \% \mathrm{Cl})$ & & & 55 & & & 54 & $100.0 \%$ & $-0.92[-2.20,0.35]$ & \\
\hline
\end{tabular}

Test for subgroup differences: $\mathrm{Chi}^{2}=1.60, \mathrm{df}=1(\mathrm{P}=0.21), \mathrm{I}^{2}=37.4 \%$

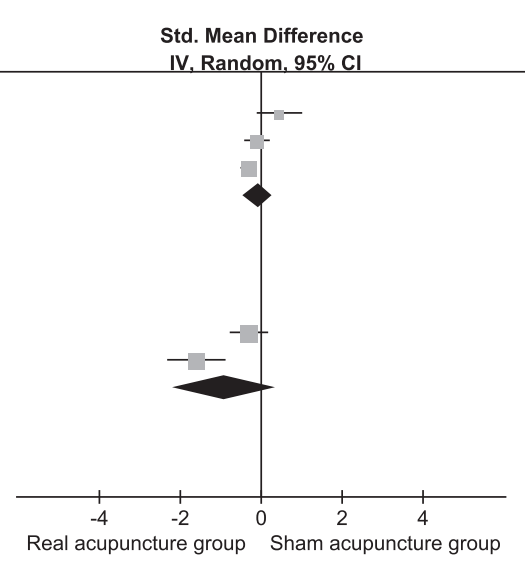

\begin{tabular}{|c|c|c|c|c|c|c|c|c|c|}
\hline \multirow{2}{*}{ Study or Subgroup } & \multicolumn{3}{|c|}{ Real acupuncture group } & \multicolumn{3}{|c|}{ Sham acupuncture group } & \multicolumn{3}{|c|}{ Std. Mean Difference } \\
\hline & Mean & SD & Total & Mean & SD & Total & Weight & IV. Random, $95 \% \mathrm{Cl}$ & Year \\
\hline \multicolumn{10}{|l|}{ 2.4.1 multicentre } \\
\hline White 2000 & 3.3 & 2.1 & 25 & 2.5 & 1.3 & 25 & $0.0 \%$ & $0.45[-0.11,1.01]$ & 2000 \\
\hline Melchart 2005 & 9.9 & 8.7 & 118 & 10.8 & 8.3 & 57 & $32.1 \%$ & $-0.10[-0.42,0.21]$ & 2005 \\
\hline $\begin{array}{l}\text { Endres } 2007 \\
\text { Subtotal }(95 \% \mathrm{Cl})\end{array}$ & 6.2 & 6.7 & $\begin{array}{l}204 \\
322\end{array}$ & 8.5 & 7.9 & $\begin{array}{l}191 \\
248\end{array}$ & $\begin{array}{r}67.9 \% \\
100.0 \%\end{array}$ & $\begin{array}{l}-0.31[-0.51,-0.12] \\
-0.25[-0.44,-0.06]\end{array}$ & 2007 \\
\hline \multicolumn{10}{|c|}{$\begin{array}{l}\text { Heterogeneity: } \mathrm{Tau}^{2}=0.00 ; \mathrm{Chi}^{2}=1.21, \mathrm{df}=1(\mathrm{P}=0.27) ; \mathrm{I}^{2}=17 \% \\
\text { Test for overall effect: } Z=2.52(P=0.01)\end{array}$} \\
\hline \multicolumn{10}{|l|}{ 2.4.2 single centre } \\
\hline Karst 2001 & 13.1 & 11.3 & 35 & 16.6 & 11.5 & 34 & $52.3 \%$ & $-0.30[-0.78,0.17]$ & 2001 \\
\hline $\begin{array}{l}\text { Xue } 2004 \\
\text { Subtotal }(95 \% \mathrm{Cl})\end{array}$ & 3 & 1.2 & $\begin{array}{l}20 \\
55\end{array}$ & 11.9 & 7.6 & $\begin{array}{l}20 \\
54\end{array}$ & $\begin{array}{r}47.7 \% \\
100.0 \%\end{array}$ & $\begin{array}{l}-1.60[-2.33,-0.88] \\
-0.92[-2.20,0.35]\end{array}$ & 2004 \\
\hline $\begin{array}{l}\text { Heterogeneity: } \mathrm{Tau}^{2}= \\
\text { Test for overall effect: }\end{array}$ & $\begin{array}{l}75 ; \mathrm{Chi}^{2}= \\
=1.42(\mathrm{P}\end{array}$ & $\begin{array}{l}9, \mathrm{df}= \\
15)\end{array}$ & $=0.0$ & 3); $1^{2}=88$ & & & & & \\
\hline
\end{tabular}

Test for subgroup differences: $\mathrm{Chi}^{2}=1.06, \mathrm{df}=1(\mathrm{P}=0.30), \mathrm{I}^{2}=5.9 \%$

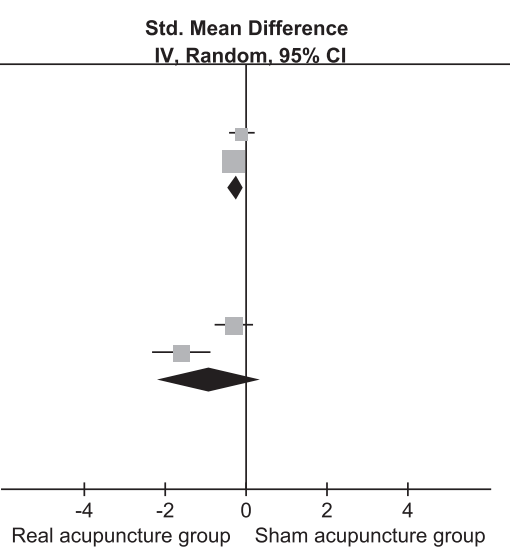

FIG. 3. (Continued).

Number for study center (multicenter versus single site). Three (3) multicentered trials were compared with two single-site studies. There was no statistically significant difference $\left(\chi^{2}=1.60, p=0.21\right)$. Heterogeneity was high among the two single site-studies $\left(\mathrm{I}^{2}=88 \%\right)$ because EA and MA were used, respectively. Removal of the one study with shortneedle retention did not change the results (Figs. 3E and 3F).

\section{A comparison of two multicenter trials}

A detailed comparison was conducted of the two multicenter studies ${ }^{5,24}$ (Table 6). Information about the trial methods of the two studies were extracted from another two publications. $^{26,27}$ They were similar in their design, but differed in outcomes, with one study showing significantly less headache days reported in the real acupuncture group than the sham group ${ }^{24}$ (SMD - 0.31; 95\% CI - 0.51 to - 0.12 ) and the other reporting no group difference ${ }^{5}$ (SMD-0.10; 95\% CI-0.42 to 0.21 ).

The two studies differed in treatment protocol and administration. In Endres' study, protocol adherence was enforced with trial monitors visiting the centers regularly; in Melchart's study, this was not described. In that study, one center did not use two out of three mandatory points as the 
Table 6. Differences of the Two Multicenter Trials

\begin{tabular}{|c|c|c|}
\hline & & Study \\
\hline & Melchart 2005 & Endres 2007 \\
\hline De qi & Required to achieve if possible & $\begin{array}{l}\text { - De qi was required on all points } \\
\text { - Repeated de qi was required (2-3 times) }\end{array}$ \\
\hline Literature support & No description & 40 acupuncture textbooks were analyzed \\
\hline $\begin{array}{l}\text { Requirement } \\
\text { on point } \\
\text { selection }\end{array}$ & No description & $\begin{array}{l}\text { Had to be formulated as precisely } \\
\text { as possible based on the appropriate } \\
\text { TCM principles }\end{array}$ \\
\hline $\begin{array}{l}\text { Classification } \\
\text { of optional } \\
\text { points selection }\end{array}$ & $\begin{array}{l}\text { - Classical acupoints } \\
\text { - Microsystem points } \\
\text { - Ah-Shi points } \\
\text { - Trigger points }\end{array}$ & $\begin{array}{l}\text { - Channels } \\
\text { - Internal level Chinese syndrome } \\
\text { - Ah-Shi points } \\
\text { - Symptomatic points }\end{array}$ \\
\hline $\mathrm{CM}$ diagnosis & $\begin{array}{l}\text { - A traditional Chinese syndrome } \\
\text { diagnosis was requested, } \\
\text { but not mandatory }\end{array}$ & $\begin{array}{l}\text { - Identifying affected meridians } \\
\text { - Identification of TCM syndrome patterns } \\
\text { - Tongue diagnosis was used additionally } \\
\text { - A predefined questionnaire was designed } \\
\text { - Mimicking an individualized TCM acupuncture } \\
\text { procedure }\end{array}$ \\
\hline Administration & $\begin{array}{l}\text { Physicians were free to choose } \\
\text { needle length and diameter } \\
\text { - Recommendations for additional } \\
\text { points were made, but practitioners } \\
\text { were free to choose others } \\
\text { - One center did not use basic points } \\
\text { on patients }\end{array}$ & $\begin{array}{l}\text { - Type of needles and intensity of needle } \\
\text { stimulation, minimum and maximum number } \\
\text { of needles to be inserted were consistent } \\
\text { during treatment } \\
\text { - Independent clinical monitors were set }\end{array}$ \\
\hline
\end{tabular}

CM, Chinese Medicine; TCM, Traditional Chinese Medicine.

points were considered unnecessary by the trial practitioners at the center. Data from the center were excluded from the final outcome. Nevertheless, the incident highlighted the importance of protocol adherence and trial monitoring.

\section{Discussion}

Results from meta-analysis showed no statistically significant difference between real and sham acupuncture on headache days. Through subgroup analyses, it was found that mode of acupuncture stimulation, duration of needle retention, and frequency of treatment could be the contributing factors to a lack of difference. In clinical practice, a typical acupuncture treatment involves 20-30 minutes of needling retention, repeated de qi sensation or stimulation, and daily or twice-weekly treatment. This review conforms to the importance of these factors. Trials with acupuncture treatment that neglect these factors might have provided suboptimal treatments, leading to a lack of difference between real and sham acupuncture.

The impact of the number of trial centers on the outcome of acupuncture treatment for TTH is not clear. Through qualitative analysis of two multicenter trials, it was further identified that adherence to treatment protocol could be another key contributing factor for multicenter trials.

\section{A comparison with other reviews}

Among four existing meta-analyses comparing the effectiveness of real with sham acupuncture intervention, ${ }^{1,4,10,28,29}$ only two used the headache days as one of the outcome measures, ${ }^{1,10}$ including the latest Cochrane review by Linde and colleagues finding that real acupuncture was significantly better than sham acupuncture on reducing headache days (WMD-1.56; 95\% CI-3.02 to -0.10), and the other by Davis that reported no difference between the two interventions, the same as ours.

The Linde review restricted trials to those with 8 weeks or more observation period after randomization. As a result, they included four out of five studies selected for the current review and excluded one EA study with a 6-week treatment period. This EA study was included because it meets the authors' criteria, and a 6-week observation period was considered sufficient to detect the short-term effect of acupuncture. The Davis review included the same five studies as those of the current review. The EA study increased the heterogeneity of the metaanalysis, resulting in no difference between real and sham acupuncture. The Linde review reported small heterogeneity of $\mathrm{I}^{2}=13 \%$, and we reported a large heterogeneity of $\mathrm{I}^{2}=81$.

The main aim of this review was to utilize subgroup analyses to explore the source of heterogeneity, which was not conducted in either of the two reviews. Subgroup analyses are frequently used to extract valuable information from RCTs. ${ }^{30-32}$ It has also been applied in acupuncture systematic reviews to investigate and interpret heterogeneity. ${ }^{33}$ To ensure that only high-quality studies were included, this review employed three commonly used scales (i.e., Jadad, IVS, and OPVS), considering selection bias, performance bias, and attrition bias, as well as the sample size and outcome measures used in pain studies. All five studies were found to be of high reporting and methodological quality. 


\section{Adequacy of acupuncture treatment and reporting of treatment details}

Adequacy of acupuncture treatment is as important as methodological quality when considering the validity of the conclusions. ${ }^{34-37}$ However, the adequacy and quality of treatment was seldom assessed in the existing systematic reviews of acupuncture. ${ }^{34}$ A recent study using the Dephi method $^{15}$ identified contributing factors as recommended by experts. Mode of acupuncture, frequency of treatment, and needle manipulation, identified in the current review, were also recommended by experts as key contributing factors.

Stimulation mode: EA versus MA. In this review, the study with EA produced a better result in headache reduction than MA did. EA has found by other researchers to be effective in reducing pain. ${ }^{38,39} \mathrm{Up}$ to now, there has not been any study directly comparing EA with MA on TTH. However, comparisons were made in some health conditions, and EA was better than MA in treating patients with tennis elbow, ${ }^{40}$ knee osteoarthritis, ${ }^{41}$ and fibromyalgia syndrome. ${ }^{33}$

When measured with functional magnetic resonance imaging, EA produced a more widespread signal increase in the brain than MA did. ${ }^{42}$ In addition, a greater analgesic effect was found when comparing EA with MA or sham acupuncture. $^{43}$

Needle retention and treatment frequency. In most acupuncture clinical trials for headache, 20-30-minute treatments with more than 10 minutes of needle retention per session were applied. ${ }^{44-48}$ However, standards or guidelines of needle retention time are not available for TTH treatment currently. A study for cerebral palsy reported that the group with needle retention of 30 minutes had better results than the group with 5-minute needle retention. ${ }^{49}$ One recent study also identified EA of 15-20 minutes was better than that of 5 or 10 minutes. ${ }^{50}$

Another factor is the frequency of treatment. One (1) study in this review applied weekly treatment, which was regarded as being insufficient to produce an analgesia effect. ${ }^{51}$ Short needle retention time together with inadequate acupuncture treatment frequency (e.g., weekly 5-minute treatment) could underestimate the treatment effect. ${ }^{52}$

Other factors identified. Other potential factors identified through qualitative analyses of the data in this reviews are de qi, point selection, CM diagnosis, background of trial acupuncturist, and adherence to trial protocol. Due to insufficient data, subgroup analyses were not conducted.

de $q i$ is regarded as the essential part of acupuncture and the predictor of a positive outcome during an acupuncture treatment. ${ }^{51}$ A strong correlation between de qi and analgesic effect was found in healthy humans. ${ }^{53}$

Studies included in this review had two categories of point selection (i.e., fixed or semistandardized point selection) like many other acupuncture studies ${ }^{54-59}$. However, fixed, a predetermined acupuncture treatment protocol was not suggested in headache clinical trials, ${ }^{60}$ given the varieties of headache presentations.

Individualized or semistandardized point selection requires standard CM diagnosis of TTH. Variations in these studies indicate a need to establish the CM differentiation diagnosis of TTH before further trials are conducted.
Multicenter studies inevitably encounter more problems than single-center trials, especially in nonpharmacological studies. As described previously, delivery of intervention could vary from one center to another even when the same protocol is used. In addition, the quality of nonpharmacological treatment largely relies on the skills and experience of the trial practitioners. As a result, skilled practitioners and reporting and assessment on protocol adherence are imperative. ${ }^{61}$ Careful monitoring is necessary for ensuring the credibility of the results. ${ }^{62}$

\section{Strengths and limitations}

This review is among the first studies that explore the contributing factors to inconsistent findings from systematic reviews of acupuncture on TTH. It does not aim to assess the effect and safety of acupuncture for TTH as other systematic reviews aimed to achieve. As a result, all sham-acupuncture controlled trials were included without including studies comparing real acupuncture with no acupuncture or other active treatments. Authors of two studies with insufficient data $^{23,25}$ were contacted, but no reply was obtained from them. Also, Chinese literature was systematically searched from the leading Chinese databases, but none met the selection criteria.

The limitation of this review is the small sample size with only five studies meeting the selection criteria. As a result, some potential factors, such as obtaining de qi during the treatment, CM diagnosis, and point selection were not able to be explored. Furthermore, the conclusion of the current review is limited by the weakness of subgroup analyses, which help identify the source of heterogeneity, but do not provide definite answers as studies that directly compare the factors do. For instance, EA was found to be better than MA in the current review. A definite conclusion can only be drawn when EA and MA are compared in a study.

A consensus on quality acupuncture needs to be reached. The Delphi study by Smith and colleagues has provided the first step. The present review illustrates the importance of some factors. The factors identified from the Delphi and this review should be assessed via subgroup analyses planned in systematic reviews of acupuncture and purposely designed trials in patients and healthy humans.

\section{Implications and Conclusions}

Stimulation mode, needle retention, and treatment frequency are important factors contributing to the outcome of acupuncture treatment for TTH. For clinical practice, the ideal acupuncture treatment protocol for TTH could be EA with 30 minutes needle retention and twice-weekly treatment. Further studies comparing EA with MA and comparing individualized treatment with standard formula are needed. Researchers also need to consider number of trial sites, practitioner training, and protocol adherence. To ensure that systematic reviews and trials of acupuncture are of high quality, consensus on quality acupuncture treatment and administration need to be established with evidencebased approaches.

\section{Disclosure Statement}

No competing financial interests exist. 


\section{References}

1. Linde K, Allais G, Brinkhaus B, et al. Acupuncture for tension-type headache. Cochrane Database Syst Rev 2009;1:CD007587.

2. Vincent CA. The treatment of tension headache by acupuncture: a controlled single case design with time series analysis. J Psychosom Res1990;34:5:553-561.

3. Xue CC, Dong L, Polus B, et al. Electroacupuncture for tension-type headache on distal acupoints only: A randomized, controlled, crossover trial. Headache 2004;44:333-341.

4. Linde K, Vickers A, Hondras M, et al. Systematic reviews of complementary therapies-An annotated bibliography: Part 1: Acupuncture. BMC Complement Altern Med 2001;1:3.

5. Melchart D, Streng A, Hoppe A, et al. Acupuncture in patients with tension-type headache: Randomised controlled trial. BMJ 2005;331:376-382.

6. Tavola T, Gala C, Conte G, Invernizzi G. Traditional Chinese acupuncture in tension-type headache: A controlled study. Pain 1992;48:325-329.

7. White AR, Eddleston C, Hardie R, et al. A pilot study of acupuncture for tension headache, using a novel placebo. Acupunct Med 1996;14:11-15.

8. Linde K, Niemann K, Schneider A, Meissner K. How large are the nonspecific effects of acupuncture? A meta-analysis of randomized controlled trials. BMC Med 2010;8:75.

9. Hopton A, MacPherson H. Acupuncture for chronic pain: Is acupuncture more than an effective placebo? A systematic review of pooled data from meta-analyses. Pain Pract 2010; 10:94-102.

10. Davis MA, Kononowech RW, Rolin SA, Spierings EL. Acupuncture for tension-type headache: A meta-analysis of randomized, controlled trials. J Pain 2008;9:667-677.

11. Jedel E, Carlsson J. Acupuncture in the management of tension-type headache. Phys Ther Rev 2005;10:131-139.

12. Granato A, Chiodo Grandi F, Stokelj D, et al. Acupuncture in tension-type headache. Neuroepidemiology 2010;35:160-162.

13. Campbell M, Fitzpatrick R, Haines A, et al. Framework for design and evaluation of complex interventions to improve health. BMJ 2000;321:694-696.

14. Paterson C, Dieppe P. Characteristic and incidental (placebo) effects in complex interventions such as acupuncture. BMJ 2005;330:1202-1205.

15. Smith CA, Zaslawski CJ, Zheng Z, et al. Development of an instrument to assess the quality of acupuncture: Results from a delphi process. J Altern Complement Med 2011;17:441-452.

16. Bendtsen L, Bigal ME, Cerbo R, et al. Guidelines for controlled trials of drugs in tension-type headache: Second edition. Cephalalgia 2010;30:1-16.

17. Jadad AR, Moore RA, Carroll D, et al. Assessing the quality of reports of randomized clinical trials: Is blinding necessary? Control Clin Trials 1996;17:1-12.

18. Linde K, Clausius N, Ramirez G, et al. Are the clinical effects of homeopathy placebo effects? A meta-analysis of placebocontrolled trials. Lancet 1997;350:834-843.

19. Smith LA, Oldman AD, McQuay HJ, Moore RA. Teasing apart quality and validity in systematic reviews: An example from acupuncture trials in chronic neck and back pain. Pain 2000;86:119-132.

20. Higgins JPT, Green S, eds. Cochrane Handbook for Systematic Reviews of Interventions. Version 5.1.0 [updated March 2011] The Cochrane Collaboration, 2011. Online document at: www.cochrane-handbook.org (accessed on 30 May 2011).
21. Wang $Y$, Zheng Z, Xue CC. Acupuncture for migraine: A systematic review of Chinese literature. Aust J Acupunct Chin Med 2008;3:3-16.

22. Higgins JP, Thompson SG, Deeks JJ, Altman DG. Measuring inconsistency in meta-analyses. BMJ 2003;327:557-560.

23. White AR, Resch KL, Chan JC, et al. Acupuncture for episodic tension-type headache: A multicentre randomized controlled trial. Cephalalgia 2000;20:632-637.

24. Endres HG, Bowing G, Diener HC, et al. Acupuncture for tension-type headache: A multicentre, sham-controlled, patient-and observer-blinded, randomised trial. J Headache Pain 2007;8:306-314.

25. Karst M, Reinhard M, Thum $P$, et al. Needle acupuncture in tension-type headache: A randomized, placebo-controlled study. Cephalalgia 2001;21:637-642.

26. Melchart D, Streng A, Hoppe A, et al. The acupuncture randomised trial (ART) for tension-type headache: Details of the treatment. Acupunct Med 2005;23:157-165.

27. Molsberger AF, Boewing G, Diener HC, et al. Designing an acupuncture study: The nationwide, randomized, controlled, German acupuncture trials on migraine and tensiontype headache. J Altern Complement Med 2006;12:237-245.

28. Sun Y, Gan TJ. Acupuncture for the management of chronic headache: A systematic review. Anesth Analg 2008;107: 2038-2047.

29. Melchart D, Linde K, Fischer P, et al. Acupuncture for recurrent headaches: A systematic review of randomized controlled trials. Cephalalgia 1999;19:779-786.

30. Sun X, Briel M, Busse JW, et al. The influence of study characteristics on reporting of subgroup analyses in randomised controlled trials: Systematic review. BMJ 2011;342:d1569.

31. Wang R, Lagakos SW, Ware JH, et al. Statistics in medicine: Reporting of subgroup analyses in clinical trials. NEJM 2007;357:2189-2194.

32. Hernandez AV, Boersma E, Murray GD, et al. Subgroup analyses in therapeutic cardiovascular clinical trials: Are most of them misleading? Am Heart J 2006;151:257-264.

33. Langhorst J, Klose P, Musial F, et al. Efficacy of acupuncture in fibromyalgia syndrome: A systematic review with a metaanalysis of controlled clinical trials. Rheumatology (Oxf) 2010;49:778-788.

34. Birch S. Problems with systematic reviews of acupuncture: What should we do about these? Clin Acupunct Oriental Med 2003;4:105-108.

35. White A, Cummings M, Barlas P, et al. Defining an adequate dose of acupuncture using a neurophysiological approach: A narrative review of the literature. Acupunct Med 2008; 26:111-120.

36. Birch S. Issues to consider in determining an adequate treatment in a clinical trial of acupuncture. Complement Ther Med 1997;5:8-12.

37. Deare JC, Zheng Z, Xue CC, et al. Acupuncture for Treating Fibromyalgia (Protocol). Cochrane Database Syst Rev 2008: CD007070.

38. Mbwambo ZH, Mahunnah RL, Kayombo EJ. Traditional health practitioner and the scientist: Bridging the gap in contemporary health research in Tanzania. Tanzan Health Res Bull 2007;9:115-120.

39. Ulett GA, Han S, Han JS. Electroacupuncture: Mechanisms and clinical application. Biol Psychiatry 1998;44:129-138.

40. Tsui P, Leung MC. Comparison of the effectiveness between manual acupuncture and electro-acupuncture on patients with tennis elbow. Acupunct Electrother Res 2002;27: 107-117. 
41. Vas J, White A. Evidence from RCTs on optimal acupuncture treatment for knee osteoarthritis: An exploratory review. Acupunct Med 2007;25:29-35.

42. Napadow V, Makris N, Liu J, et al. Effects of electroacupuncture versus manual acupuncture on the human brain as measured by fMRI. Hum Brain Mapp 2005;24:193-205.

43. Zheng Z, Feng SJ, Costa C, et al. Acupuncture analgesia for temporal summation of experimental pain: A randomised controlled study. Eur J Pain 2010;14:725-731.

44. Facco E, Liguori A, Petti F, et al. Traditional acupuncture in migraine: A controlled, randomized study. Headache 2008; 48:398-407.

45. Alecrim-Andrade J, Maciel-Junior JA, Cladellas XC, et al. Acupuncture in migraine prophylaxis: A randomized shamcontrolled trial. Cephalalgia 2006;26:520-529.

46. Alecrim-Andrade J, Maciel-Junior JA, Carne X, et al. Acupuncture in migraine prevention: A randomized sham controlled study with 6-months posttreatment follow-up. Clin J Pain 2008;24:98-105.

47. Linde K, Streng A, Jurgens S, et al. Acupuncture for patients with migraine: A randomized controlled trial. JAMA 2005;293:2118-2125.

48. Li Y, Liang F, Yang X, et al. Acupuncture for treating acute attacks of migraine: A randomized controlled trial. Headache 2009;49:805-816.

49. Wang QY, Feng JQ, Luo GF, Jin R. Observations on a comparison of quick needling and retained needle for treating 60 cerebral palsy cases. Shanghai J Acu-mox 2004;23:15-17.

50. Leung AY, Kim SJ, Schulteis G, Yaksh T. The effect of acupuncture duration on analgesia and peripheral sensory thresholds. BMC Complement Altern Med 2008;8:18.

51. Takeda W, Wessel J. Acupuncture for the treatment of pain of osteoarthritic knees. Arthritis Care Res 1994;7:118-122.

52. Xue CC, English R, Zhang JJ, et al. Effect of acupuncture in the treatment of seasonal allergic rhinitis: A randomized controlled clinical trial. Am J Chin Med 2002;30:1-11.

53. Kong J, Fufa DT, Gerber AJ, et al. Psychophysical outcomes from a randomized pilot study of manual, electro, and sham acupuncture treatment on experimentally induced thermal pain. J Pain 2005;6:55-64.

54. Leibing E, Leonhardt U, Köster G, et al. Acupuncture treatment of chronic low-back pain: A randomized, blinded, placebo-controlled trial with 9-month follow-up. Pain 2002;96:189-196.
55. Zaringhalam J, Manaheji H, Rastqar A, Zaringhalam M. Reduction of chronic non-specific low back pain: A randomised controlled clinical trial on acupuncture and baclofen. Chin Med 2010;5:15.

56. Cherkin DC, Sherman KJ, Hogeboom CJ, et al. Efficacy of acupuncture for chronic low back pain: Protocol for a randomized controlled trial. Trials 2008;9:10.

57. Vas J, Perea-Milla E, Mendez C, et al. Efficacy and safety of acupuncture for the treatment of non-specific acute low back pain: A randomised controlled multicentre trial protocol [ISRCTN65814467]. BMC Complement Altern Med 2006;6:14.

58. Haake M, Muller HH, Schade-Brittinger C, et al. The German multicenter, randomized, partially blinded, prospective trial of acupuncture for chronic low-back pain: A preliminary report on the rationale and design of the trial. J Altern Complement Med 2003;9:763-770.

59. Molsberger AF, Zhou J, Arndt D, Teske W. Chinese acupuncture for chronic low back pain: An international expert survey. J Altern Complement Med 2008;14:1089-1095.

60. Coeytaux RR, Chen W, Lindemuth CE, et al. Variability in the diagnosis and point selection for persons with frequent headache by traditional Chinese medicine acupuncturists. J Altern Complement Med 2006;12:863-872.

61. Boutron I, Moher D, Altman DG, et al. Extending the CONSORT statement to randomized trials of nonpharmacologic treatment: Explanation and elaboration. Ann Intern Med 2008;148:295-309.

62. Zhao L, Li Y, Zhang FW, Guang H. Quality monitoring in multi-central large sample acupuncture clinical trials [in Chinese]. Zhongguo Zhen Jiu 2008;28:835-837.

Address correspondence to: Zhen Zheng, BMed, PhD

Traditional \& Complementary Medicine Program Health Innovations Research Institute and School of Health Sciences RMIT University

Bundoora, Victoria 3083 Australia

E-mail: zhen.zheng@rmit.edu 